\title{
Is chlorophyll-a the best surrogate for organic matter enrichment in submicron primary marine aerosol?
}

\author{
Matteo Rinaldi, ${ }^{1}$ Sandro Fuzzi, ${ }^{1}$ Stefano Decesari, ${ }^{1}$ Salvatore Marullo, ${ }^{2}$ Rosalia Santoleri, ${ }^{3}$ \\ Antonello Provenzale, ${ }^{4}$ Jost von Hardenberg, ${ }^{4}$ Darius Ceburnis, ${ }^{5}$ Aditya Vaishya, ${ }^{5}$ \\ Colin D. O'Dowd, ${ }^{5}$ and Maria Cristina Facchini ${ }^{1}$
}

Received 3 August 2012; revised 10 April 2013; accepted 11 April 2013; published 28 May 2013.

[1] Initial efforts toward developing a combined organic-inorganic sea spray source function parameterization for large-scale models made use of chlorophyll- $a$ (Chl- $a$ ) and wind speed as input parameters to combine oceanic biology and atmospheric dynamics. These studies reported a modest correlation coefficient (0.55) between chlorophyll- $a$ and organic matter (OM) enrichment in sea spray, suggesting that chlorophyll- $a$ is only partially suitable for predicting organic enrichment. A reconstructed chlorophyll- $a$ field of the North Atlantic Ocean from GlobColour reveals an improved correlation of 0.72 between the fractional mass contribution of organics in sea spray and chlorophyll- $a$ concentration. A similar analysis, using colored dissolved and detrital organic material absorption and particulate organic carbon concentration, revealed slightly lower correlation coefficients $(0.65$ and 0.68$)$. These results indicate that to date, chlorophyll- $a$ is the best biological surrogate for predicting sea spray organic enrichment. In fact, considering the minimal difference between the correlation coefficients obtained with the three ocean color products, there is no reason to substitute chlorophyll- $a$, which is the most accurate parameter obtained from ocean color data, with other biological surrogates being generally affected by larger and less known errors. The observed time lag between chlorophyll- $a$ concentration and organic matter enrichment in aerosol suggests that biological processes in oceanic surface waters and their timescales should be considered when modeling the production of primary marine organic aerosol.

Citation: Rinaldi, M., et al. (2013), Is chlorophyll- $a$ the best surrogate for organic matter enrichment in submicron primary marine aerosol?, J. Geophys. Res. Atmos., 118, 4964-4973, doi:10.1002/jgrd.50417.

\section{Introduction}

[2] The existence of a source of submicron primary organic aerosol (POA), mainly from biologically active seawater, has recently been demonstrated [O'Dowd et al.,

\footnotetext{
Additional supporting information may be found in the online version of this article.

${ }^{1}$ Institute of Atmospheric Sciences and Climate, National Research Council, Bologna, Italy.

${ }^{2}$ Technical Unit for the Development of Applications of Radiations, Diagnostic and Metrology Laboratory, Italian National Agency for New Technologies, Energy and Sustainable Economic Development (ENEA), Frascati, Italy.

${ }^{3}$ Institute of Atmospheric Sciences and Climate, National Research Council, Rome, Italy.

${ }^{4}$ Institute of Atmospheric Sciences and Climate, National Research Council, Turin, Italy.

${ }^{5}$ School of Physics and Centre for Climate and Air Pollution Studies, Ryan Institute, National University of Ireland Galway, Galway, Ireland.

Corresponding author: M. Rinaldi, Institute of Atmospheric Sciences and Climate, National Research Council, via Gobetti 101, 40129, Bologna, Italy. (m.rinaldi@isac.cnr.it)

(C)2013. American Geophysical Union. All Rights Reserved. 2169-897X/13/10.1002/jgrd.50417
}

2004; Keene et al., 2007; Facchini et al., 2008; Ovadnevaite et al., 2011]. In particular, submicron marine aerosol waterinsoluble organic matter (WIOM) has been associated with sea spray aerosol [Facchini et al., 2008; Ceburnis et al., 2008]. In order to evaluate the global burden of biogenic POA from the oceans and achieve a better understanding of its relevance to climate, it is necessary to include this source in regional and global models.

[3] This paper presents an effort toward developing a combined organic-inorganic sea spray source function parameterization for use in large-scale models, using a combination of chlorophyll- $a(\mathrm{Chl}-a)$ and wind speed (WS) as primary input parameters for combining the biological and dynamical contributions. In the work reported here, the term "sea spray" is used as a synonym of primary marine aerosol, intended as composed of both sea salt and biogenic organic matter (OM), regardless of its "atmospheric age."

[4] Previous studies [O'Dowd et al., 2008; Langmann et al., 2008; Vignati et al., 2010], performed using satellite-derived chlorophyll- $a$ fields with low temporal resolution (monthly averages), reported only a modest linear correlation between chlorophyll- $a$ (Chl- $a$ ) concentration and organic matter $(\mathrm{OM})$ enrichment in sea spray (at best $r=0.55$ ). This 
suggested that Chl- $a$ is only partially suitable as a surrogate for biological activity for predicting the organic mass fraction of sea spray.

[5] Recently, Gantt et al. [2011] demonstrated that Chl-a satellite fields with a higher time resolution of 8 days can provide a higher correlation $(r=0.66)$ for an extended version of the marine aerosol database used by Vignati et al. [2010], even though, in this case, an exponential fitting was preferred to a linear one. Moreover, the cited paper compared Chl- $a$ with other ocean color parameters, namely, particulate and dissolved organic carbon, and it turned out to be the best surrogate to predict the organic matter enrichment in sea spray aerosol.

[6] To check whether satellite ocean color parameters with higher time resolution can improve the observed correlation between ocean chemistry and sea spray chemical composition and if different ocean color parameters can surpass Chl- $a$ in predicting the chemical properties of sea spray, the present work investigates the correlation between the chemical composition of submicron sea spray aerosol measured at Mace Head from 2002 to 2009 and daily satellite ocean color fields.

[7] The study by Vignati et al. [2010] was the first to apply a source function for marine primary organic aerosol derived from observations at Mace Head and satellite Chl- $a$ data, on the global scale, estimating a global emission of primary marine organic matter in the accumulation mode of 5.8 $\mathrm{TgC} \mathrm{yr}^{-1}$. This compares well with the $5.5 \mathrm{TgC} \mathrm{yr}^{-1}$ obtained by Spracklen et al. [2008], using a different topdown approach, although nonetheless based on correlations between aerosol data and satellite Chl- $a$ data. More recently, Gantt et al. [2011] also estimated a global source of the same magnitude $\left(2.8-5.6 \mathrm{TgC}^{-1}\right)$, using a source function derived from a data set encompassing that of Vignati et al. [2010], by means of a similar approach. Nevertheless, these estimates are significantly lower than those produced by other studies based on different methods. Roelofs [2008] estimated a submicron global marine organic aerosol source of $50 \mathrm{Tg} \mathrm{C} \mathrm{yr}^{-1}$, using a simple top-down approach, of which $30-50 \%$ was attributed to secondary sources, while Long et al. [2011] provided an estimate of $29 \mathrm{TgC} \mathrm{yr}^{-1}$, including, however, also the contribution from supermicron particles.

[8] The interest of the scientific community in the above preliminary approaches is reflected by further developments and deployment of the organic sea spray scheme in a number of global models [Gantt et al., 2009; Myriokefalitakis et al., 2010; Ito and Kawamiya, 2010; Westervelt et al., 2012] and provides the motivation to improve the parameterization of the organic-inorganic sea spray source function.

\section{Experimental Methods}

\subsection{Aerosol Measurements at Mace Head}

[9] Submicron marine aerosol chemical composition data collected discontinuously at the Mace Head station, on the Irish west coast, from 2002 to 2009, for a total of 52 samples, were used to calculate the organic mass fraction of submicron sea spray $\left(\mathrm{OM}_{\mathrm{SS}}\right)$, employing the equation $\mathrm{OM}_{\mathrm{SS}}=\mathrm{WIOM} /(\mathrm{WIOM}+$ sea salt $)$, first adopted by $O{ }^{\prime}$ Dowd et al. [2008]. The equation is based on the assumption that marine POA is mainly water insoluble and that water- soluble organics are mainly representative of secondary organic aerosols (SOAs). This is supported by Facchini et al. [2008], who described sea spray organics as mainly water insoluble, and by the nuclear magnetic resonance (NMR) spectroscopy analyses by Decesari et al. [2011], showing strong similarity between marine aerosol WIOM and the waterinsoluble lipopolysaccharides isolated by Facchini et al. [2008]. Moreover, SOA is typically more oxidized and therefore more water soluble than POA. The possible uncertainties in marine POA predictions related to such an assumption have been discussed by Gantt et al. [2011].

[10] The data set comprises all the samples used in previous studies [O'Dowd et al., 2008; Vignati et al., 2010], plus 27 new samples collected between 2006 and 2009. Details on aerosol sampling and chemical analyses are given by O'Dowd et al. [2008], Vignati et al. [2010], and cited references. Briefly, up to 2006, aerosol samples were collected in parallel using an eight-stage Berner impactor (BI8) and a Sierra Andersen high-volume sampler (HiVol). The BI8 was equipped with Tedlar foils, collecting particles in eight size fractions between 0.06 and $16 \mu \mathrm{m}$ diameters (cutoffs: $0.06,0.125,0.25,0.50,1.0,2.0,4.0$, and $8.0 \mu \mathrm{m}$ at $50 \%$ efficiency), and operated at a flow rate of $30 \mathrm{~L} \mathrm{~min}^{-1}$. The HiVol operated at $1 \mathrm{~m}^{3} \mathrm{~min}^{-1}$, segregating fine (aerodynamic diameter smaller than $1.5 \mu \mathrm{m}$ ) and coarse particles (aerodynamic diameter between 1.5 and $10 \mu \mathrm{m}$ ) on quartz filters. After Milli-Q water extraction, sea salt was measured on the BI8 samples by ion chromatography, following the method of Cavalli et al. [2004]. The first four stages of the impactor were summed to obtain the submicron sea salt concentration. The WIOM was determined on the fine HiVol samples by subtracting the water-soluble organic carbon (WSOC) content from the total carbon (TC) content and by multiplying for a correction factor of 1.4 to consider the mass-to-carbon ratio [Facchini et al., 2008]. Both WSOC and TC analyses were performed by an Analytik Jena multi N/C 2100 elemental analyzer, as described in Rinaldi et al. [2009]. From 2008 on, aerosol samples were collected by a LVS3 Small Filter Device (Kleinfiltergeräte) sampler (Sven Leckel Ingenieurbüro $\mathrm{GmbH}$ ), collecting particulate matter with aerodynamic diameter lower than $1 \mu \mathrm{m}$ (PM1) and operating at $48 \mathrm{~L} \mathrm{~min}^{-1}$. The device has an inlet which removes supermicron particles from sample air by impaction mechanism and collects submicron particles in bulk on a prefired $47 \mathrm{~mm}$ quartz fiber filter.

[11] A total of 37 samples was collected before 2006, accounting for $71 \%$ of the database, and 15 from 2008 on. Although the database was obtained with data derived by two different methods, it can be considered homogeneous as the two data subsets, comprising at least one complete year each, present very similar $\mathrm{OM}_{\mathrm{SS}}$ data distributions $(34 \%, 23.3 \%, 32 \%, 2 \%$, and $78 \%$ versus $34 \%, 16.4 \%$, $39 \%, 10 \%$, and $63 \%$ in terms of average, standard deviation, median, minimum, and maximum), suggesting that the two sampling methods are comparable and none of the two was biased toward the estimate of $\mathrm{OM}_{\mathrm{SS}}$. Moreover, a Kolmogorov-Smirnov (KS) test performed on the two data subsets does not reject the null hypothesis that the two samples are drawn from the same distribution (with KS statistics $\mathrm{D}=0.23$ and consequently a probability that two random samplings of the same distribution produce the same or a larger value $\mathrm{D}$ of $\mathrm{p}=0.56$ ). 


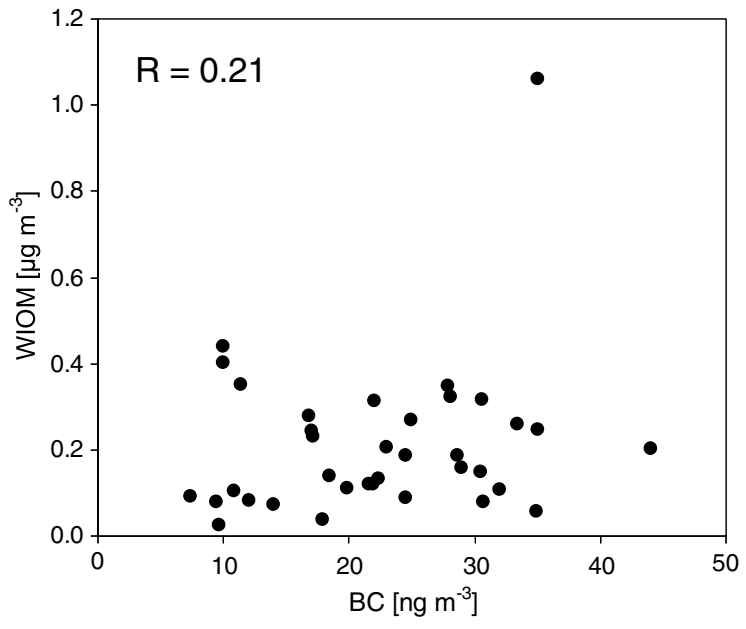

Figure 1. WIOM versus $\mathrm{BC}$ for the aerosol samples used to derive the organic-inorganic sea spray source function parameterization.

[12] Since all the samplers collected particles at ambient relative humidity, all of the diameters cited henceforth should be taken to be aerodynamic diameters at ambient relative humidity, as defined by the sampler cutoff.

[13] All the aerosol samples were collected by an active sector-controlled sampling system developed to avoid anthropogenic contamination. The computer-based system used wind direction (see below for details regarding wind measurements) to sample onshore air masses and also a condensation particle counter (TSI 3010) to trigger sampling shutdown when counts exceeded 700 particles $\mathrm{cm}^{-3}$. This low level not only excluded incursions of polluted air but also excluded coastal nucleation events and, consequently, any coastal influences. Such a cautious approach also aimed to exclude the open ocean nucleation events recently documented by O'Dowd et al. [2010], causing a modest increase of particle number concentration up to $1500 \mathrm{~cm}^{-3}$. In addition, the active control of sampling conditions excluded sampling during occasional short-term spikes in particle concentration due to sporadic local shipping traffic. A postsampling analysis revealed these air masses did not reach land for 4-5 days (as confirmed by air mass back trajectories) and black carbon (BC) concentrations measured by an aethalometer (AE-16, Magee Scientific, with single wavelength at $880 \mathrm{~nm}$ ) did not exceed $50 \mathrm{ng} \mathrm{m}^{-3}$ and were typically about $35 \mathrm{ng} \mathrm{m}^{-3}$. The air masses had spent the previous $48 \mathrm{~h}$ (at least) in the marine boundary layer, as evidenced by Cavalli et al. [2004] and Ceburnis et al. [2011]. The clean sector selection criteria were identical for all the samples used in the present study.

[14] Ceburnis et al. [2011] used carbon isotope analysis $\left({ }^{13} \mathrm{C}\right.$ and $\left.{ }^{14} \mathrm{C}\right)$ to quantify anthropogenic, marine biogenic, and terrestrial nonfossil carbon sources in submicron particles over the northeast Atlantic Ocean, deploying a subset of the samples used in this study. The contribution of anthropogenic carbon in marine air masses sampled by the sectorcontrolled system accounted for as little as 8-20\%, confirming that the organics observed in the samples were mainly marine biogenic in origin. Similarly, the results of Decesari et al. [2011], based on the factor analysis of NMR spectra of marine aerosol WSOC, collected with the same system, show a contribution of anthropogenic sources at Mace Head of $17 \%$ on average.

[15] Moreover, different from that in Shank et al. [2012], no correlation was observed in the data set between WIOM and $\mathrm{BC}$ data (Figure 1). This further confirms that the contribution of anthropogenic sources is of minor importance in the samples collected at Mace Head with the sectorcontrolled system and that the observed WIOM is mainly biogenic.

[16] The term "clean marine air masses" used herein refers to air masses selected by the above system, following the criteria previously described.

[17] Samples were collected with a typical exposure time of 1 week (with a small subset of the samples collected over a period of up to 15 days). During the period, the effective sampling time was limited to the occurrence of clean marine sector conditions (as described above) with a typical sampling duration of $30-150 \mathrm{~h}$.

[18] The 52 samples constituting the data set are representative of the different conditions encountered at Mace Head over the year, with samples collected during the season of high biological activity, the quiescent period, and the transition periods. More in detail, winter, summer, and autumn are equally represented, each accounting for approximately $20 \%$ of the samples, while the remaining $40 \%$ were collected during spring. The representativeness of the data set was further investigated by comparing the probability distribution of wind speed (WS; see below for details) during the sampling periods with that measured from 2002 to 2009 at Mace Head in clean marine conditions, as defined by the active sectorcontrolled sampling system. WS was selected as the reference meteorological parameter as it drives the production of sea spray. Figure 2 shows a very good degree of agreement between the two WS probability distributions, supporting the representativeness of the data set with respect to the meteorological conditions occurring at Mace Head during periods of marine air advection.

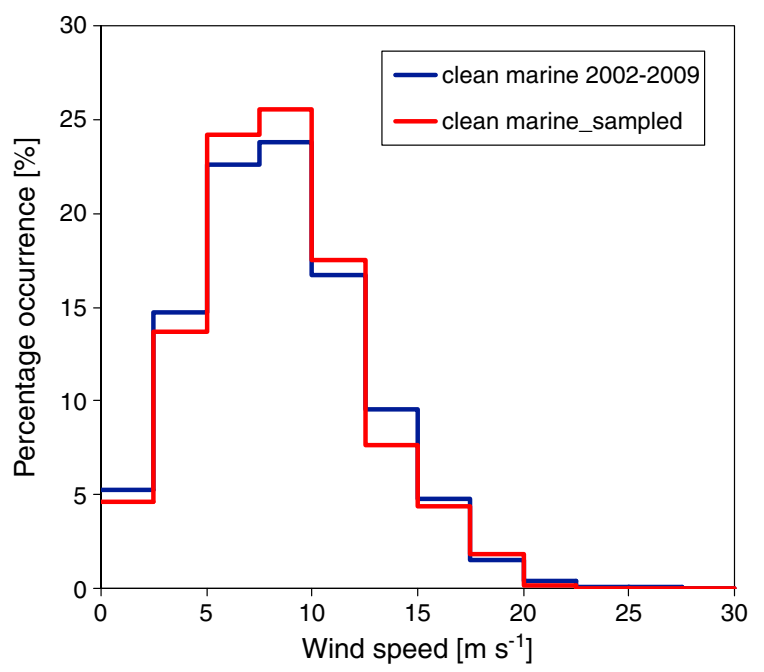

Figure 2. Wind speed probability distribution at Mace Head. The blue curve refers to clean marine air mass conditions from 2002 to 2009, as defined by the sector-controlled sampling system, while the red one to the subset of the sampling periods. 
[19] WS and direction were measured on the $10 \mathrm{~m}$ tower at Mace Head by a Vector Instruments wind monitor (model W200P/A100L) with a resolution of $3 \mathrm{~s}$. Data were then averaged to hourly values, and only periods overlapping with aerosol sampling time, corresponding to clean marine air masses, were taken into consideration. The coastal measurements were extensively compared with offshore wind data by Gantt et al. [2011] (auxiliary material), who found a very good level of agreement.

\subsection{Ocean Color Data Treatment}

[20] Daily satellite ocean color data from 1998 to 2010, with $1^{\circ}$ spatial resolution, were obtained from the GlobColour data set, developed in the framework of the European Space Agency Data User Element program to support global carbon cycle research. In detail, use was made of fully normalized water-leaving radiances (nLw), chlorophyll- $a$ concentration, and colored dissolved and detrital organic material absorption (CDM). The daily GlobColour data are available on the Web sites of GlobColour (http://www.globcolour.info) and MyOcean (http://www.myocean.eu/).

[21] The GlobColour products were obtained by merging Medium-Resolution Imaging Spectrometer (MERIS), Moderate Resolution Imaging Spectroradiometer (MODIS), and Sea-viewing Wide Field-of-view Sensor (SeaWiFS) data using advanced retrieval based on fitting an in-water biooptical model to the merged set of observed normalized water-leaving radiances. The technique is referred to as GSM because it originates from the Garver-SiegelMaritorena bio-optical model [Maritorena and Siegel, 2005].

[22] The use of the three sensors reduced the data gaps while increasing the coverage over ocean by a factor which is nearly twice that of any single mission's observations [Maritorena et al., 2010]. The GlobColour products were validated by Maritorena et al. [2010], who performed matchup analyses (e.g., comparison between corresponding in situ and satellite data) and compared them with the data sets obtained from individual missions.

[23] We computed seawater particulate organic carbon (POC) concentration following the approach described by Stramska [2009], starting from remote sensing reflectances derived from GlobColour $\mathrm{nLw}$ and the corresponding extraterrestrial solar irradiance F0. It should be pointed out that here, POC refers to seawater particulate matter, as is standard terminology in marine biology and the ocean color community, and not to atmospheric aerosols. Therefore, to avoid any confusion to readers, who are likely to come from the atmospheric sciences community, the expression "seawater POC" (SW-POC) will be used henceforth.

[24] Missing data are a typical problem in the analysis of time series of satellite data. In fact, depending on the type of instrumentation, remote sensing is influenced by atmospheric conditions and can be hampered by clouds, aerosols, or heavy precipitation. The availability of ocean color data is mainly limited by the presence of clouds. Data voids represent a problem in the analysis and modeling of the spatiotemporal variability of ocean color derived parameters, biasing the analysis to good weather conditions and distorting the oscillatory modes upon which the observed satellite time series are based. Gap-filling methods can alleviate such problems by extracting the most significant oscillatory modes from the time series, thus allowing a more quantitative comparison with other independent time series.

[25] Multichannel singular spectrum analysis (M-SSA) was used to fill daily gaps in Chl- $a$, CDM, or SW-POC maps due to cloud cover or other environmental factors. The method (Appendix A) uses temporal, as well as spatial, correlations to fill in the missing points [Ghil et al., 2002; Kondrashov and Ghil, 2006].

[26] It was borne in mind that due to atmospheric correction algorithm limits, only ocean color data with solar zenith angle less than $75^{\circ}$ are permitted [Wang, 2002; Gregg and Casey, 2007] and that $70^{\circ}$ is the maximum angle for which atmospheric correction algorithms based on plane-parallel radiative transfer calculations have been developed. Thus, the interpolation of the data voids was conservatively limited to areas where the absolute value of the Sun zenith angle was below $70^{\circ}$, also excluding polar night conditions.

[27] Given that the aerosol samples were collected at Mace Head with filter exposition times of several days, satellite data had to be averaged in order to produce the average values of Chl- $a$, CDM, and SW-POC to associate with each aerosol sample. To this end, the time window for the satellite data averaging was set as identical to the filter exposition time of each sample, using different time lags between the averaging period and the filter exposition start time, from 0 to 15 days. The correlation coefficients between $\mathrm{OM}_{\mathrm{SS}}$ and the ocean color products, obtained by standard least squares regression, at each grid point of a domain covering the northeastern Atlantic Ocean and for each time lag, were computed to obtain correlation maps.

\section{Results}

[28] The results of the correlation analysis are reported in Figure 3 , in the form of correlation maps, while the whole data set is reported in the auxiliary material. In the maps, the colors represent the correlation coefficient $(r)$ resulting from the regression analysis between Chl- $a$, CDM, or SW-POC and $\mathrm{OM}_{\mathrm{SS}}$ at each point of the domain. Analysis of the correlation maps obtained with different time lags between the satellite data averaging time window and the filter exposition time (see section 2.2) shows that the maximum correlation, within the broad oceanic region facing Mace Head $\left(40-60^{\circ} \mathrm{N}\right.$ and $\left.10-30^{\circ} \mathrm{W}\right)$, is found with a time lag of 8 days for Chl- $a$ and SW-POC and of 10 days for CDM (Figure 4). The maps corresponding to the maximum correlation time lags have been selected and reported in Figure 3. The delay of about 1 week between the Chl- $a$, $\mathrm{CDM}$, and SW-POC time series with respect to $\mathrm{OM}_{\mathrm{SS}}$, while the typical travel time for an air parcel between the above region and the Mace Head station is of the order of 1-2 days, might be the result of the biological processes responsible for the production of transferable organic material during the bloom evolution, which are not necessarily in phase with Chl- $a$, CDM, and SW-POC. This could be an important parameter to consider for the implementation of the source function into models and a possible explanation for certain disagreements previously observed between models and measurements [e.g., O'Dowd et al., 2008; Vignati et al., 2010]. However, the resolution of the aerosol data is too limited to attribute firm significance to the observed time delay, and further investigation is required to better assess the role 

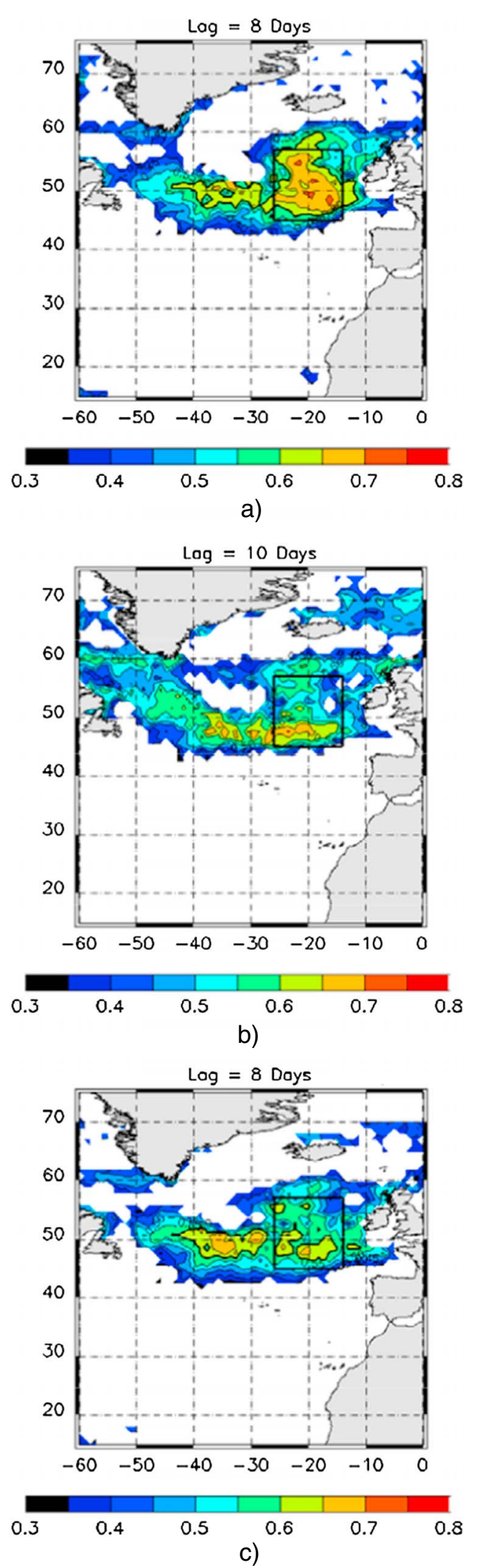

Figure 3. Correlation maps for (a) Chl-a, (b) CDM, and (c) SW-POC. Colored regions represent areas where the correlation was significant at the $95 \%$ confidence level. The box indicates the area selected to compute the regression curves reported in Figure 4 (see text for details). and typical timescales of biological processes producing transferable organic material at the ocean surface.

[29] The maps in Figure 3 clearly identify the oceanic region exerting the maximum influence on the chemical composition of the sea spray aerosol measured at Mace Head, i.e., the area where the correlation between ocean parameters and $\mathrm{OM}_{\mathrm{SS}}$ is maximum (black squares in Figures $3 \mathrm{a}, 3 \mathrm{~b}$, and $3 \mathrm{c}$ ). The region is located west of Mace Head, between 47 and $57^{\circ} \mathrm{N}$ and between 14 and $24^{\circ} \mathrm{W}$. The oceanic region identified here corresponds quite closely to the Chl- $a$ data averaging region chosen by O'Dowd et al. [2008] based on back trajectory analysis of the air masses affecting Mace Head during the aerosol sampling.

[30] Averaging Chl- $a$ and SW-POC concentrations and CDM absorption in the maximum correlation area (see above) reveals linear relationships between the three ocean color parameters and $\mathrm{OM}_{\mathrm{SS}}$ (Figure 5). The relationships are as follows:

$$
\begin{gathered}
\mathrm{OM}_{\mathrm{SS}}=75.9 \times \text { Chl- } a-3.99 \\
\mathrm{OM}_{\mathrm{SS}}=2455 \times \mathrm{CDM}-37.8 \\
\mathrm{OM}_{\mathrm{SS}}=0.709 \times \mathrm{SW}-\mathrm{POC}-34.7
\end{gathered}
$$

where Chl- $a$ and SW-POC are expressed as $\mathrm{mg} \mathrm{m}^{-3}, \mathrm{CDM}$ as $\mathrm{m}^{-1}$, and $\mathrm{OM}_{\mathrm{SS}}$ as percentage units. Consistent with the results described above, time lags of 8,10 , and 8 days for Chl- $a$, CDM, and SW-POC have been considered, respectively. The three relations are characterized by correlation coefficients $r=0.72,0.65$, and 0.68 for Chl- $a$, CDM, and SW-POC, respectively. Considering the minimal differences among the correlation coefficients and the fact that chlorophyll- $a$ is the most widely available and validated ocean color parameter, there is no reason to substitute chlorophyll- $a$ by other biological surrogates, which might be affected by larger errors and based on less tested algorithm parameters estimates [Maritorena et al., 2010].

[31] The use of highly time-resolved Chl- $a$ maps, with the appropriate data treatment and time lag, reduces the dispersion of data around the best fit line and increases the correlation coefficient of the mixed organicinorganic sea spray source function. In fact, the presented Chl $a-\mathrm{OM}_{\mathrm{SS}}$ linear relation has a correlation coefficient far higher than those previously proposed (e.g., 0.55 in Vignati et al. [2010]). Gantt et al. [2011], operating an exponential fitting, obtained a lower correlation coefficient (0.66) for a subset of the aerosol database used in this work (37 samples out of 52) and 8 day averaged SeaWiFS chlorophyll- $a$ fields.

[32] The $\mathrm{Chl} a-\mathrm{OM}_{\mathrm{SS}}$ linear relationship reported in equation (1) is characterized by a higher slope than the source function presented in Vignati et al. [2010]. The implementation of this new source function in a global model is beyond the province of this paper. Nevertheless, it can be argued that the new function will modify the results of Vignati et al. [2010], by reducing POA emission in chlorophyll- $a$ depleted waters and increasing emission under high chlorophyll- $a$ concentrations. Given that a general overestimation of WIOM concentration in low-chlorophyll conditions was reported by 


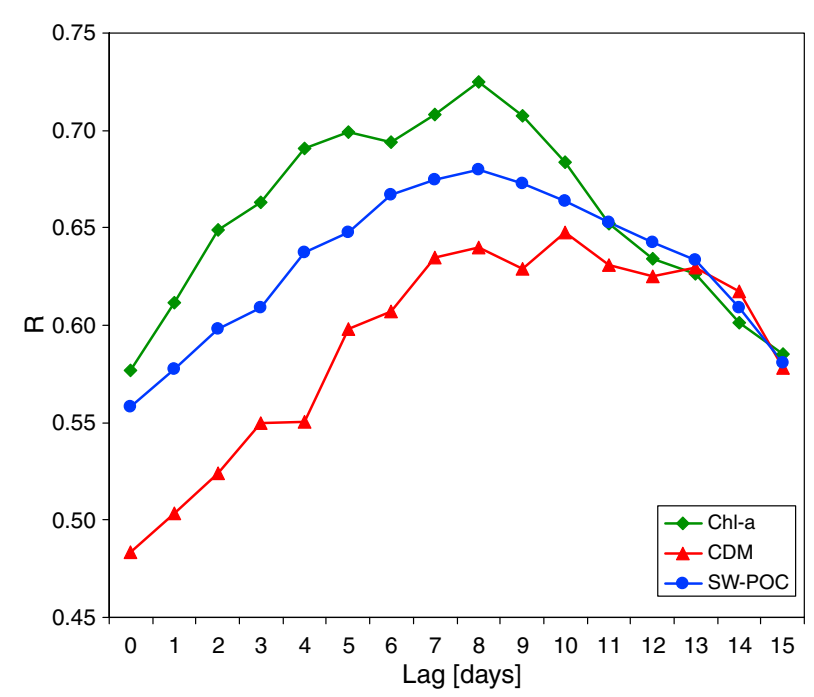

Figure 4. Dependency of the correlation between Chl- $a$, CDM, and SW-POC and $\mathrm{OM}_{\mathrm{SS}}$ as a function of the time lag between the satellite data averaging time window and the filter exposition start time at Mace Head.

Vignati et al. [2010], with respect to measurements performed at Mace Head, this result is encouraging.

[33] Gantt et al. [2011] demonstrated that the fractional contribution of organic matter in sea spray does depend not only on marine biology but also on a physical parameter, namely, WS. More precisely, they found a significant inverse correlation between $\mathrm{OM}_{\mathrm{SS}}$ and WS in two marine aerosol data sets, one of which was a subset of the data set used in the present study. It is worth highlighting that the inverse dependency on WS relates only to $\mathrm{OM}_{\mathrm{SS}}$, i.e., the fractional contribution of organic matter in sea spray aerosol, and not to the absolute concentration of sea spray, which is still enhanced under high-WS conditions. The observed correlation $\left(\mathrm{OM}_{\mathrm{SS}}\right.$ versus WS) was explained by the formation of a thick, stable sea surface microlayer (which can be extremely enriched in organics in high biological activity conditions) under low-WS conditions, enhancing the transfer of organics to the atmosphere through the bubble bursting process. For the same degree of biological activity, high wind speeds drive a continuous mixing of the organic-enriched layer with below-surface waters, which are poorer in organics, resulting in the reduction of sea spray enrichment.

[34] The inverse correlation between $\mathrm{OM}_{\mathrm{SS}}$ and WS was confirmed in the extended data set used in the present study (slope $=-7.29 \pm 2.57 \mathrm{~s} \mathrm{~m}^{-1}$, intercept $=91.11 \pm 19.9 \%$, and $r=-0.65)$. As a consequence, in order to derive a reliable relation to predict the fractional contribution of OM in sea spray aerosol, a two-dimensional regression analysis between $\mathrm{OM}_{\mathrm{SS}}$, Chl- $a$, and WS was deemed necessary. The result of this correlation analysis is reported in Figure 6 and equation (4):

$$
\begin{aligned}
\mathrm{OM}_{\mathrm{SS}} & =(56.9 \times \mathrm{Chl}-a)+(-4.64 \times \mathrm{WS}) \\
& +40.9(r=0.82)
\end{aligned}
$$

where Chl- $a$ is expressed as $\mathrm{mg} \mathrm{m}^{-3}$, WS as $\mathrm{ms}^{-1}$, and $\mathrm{OM}_{\mathrm{SS}}$ as percentage units. It is worth noting that the correlation coefficient of the regression curve is further increased once the reverse correlation with WS is introduced in the system.

[35] As a conclusion of this study, we propose equation (4) as a novel organic-inorganic sea spray source function

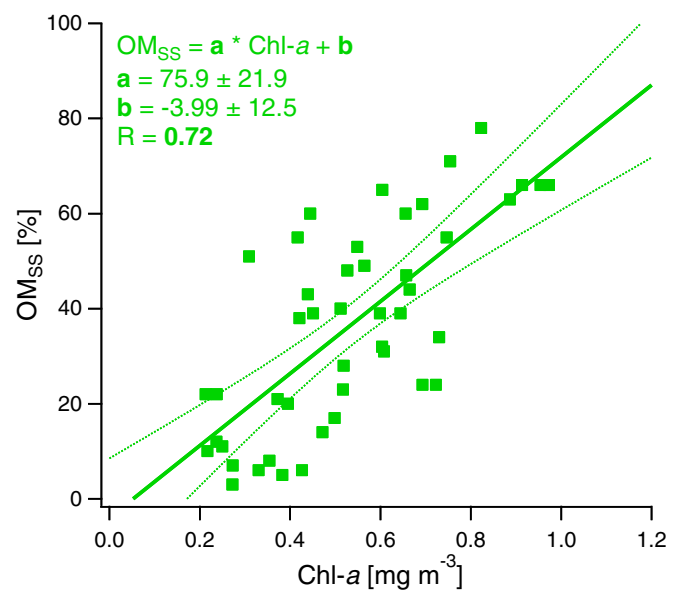

a)

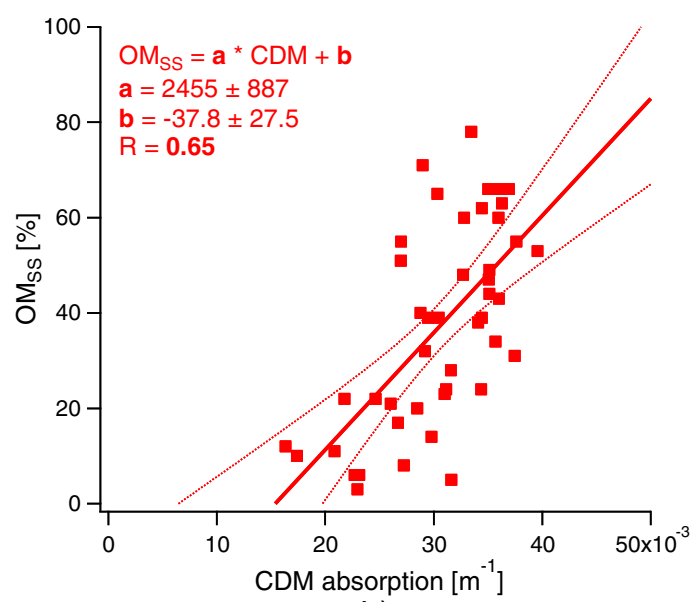

b)

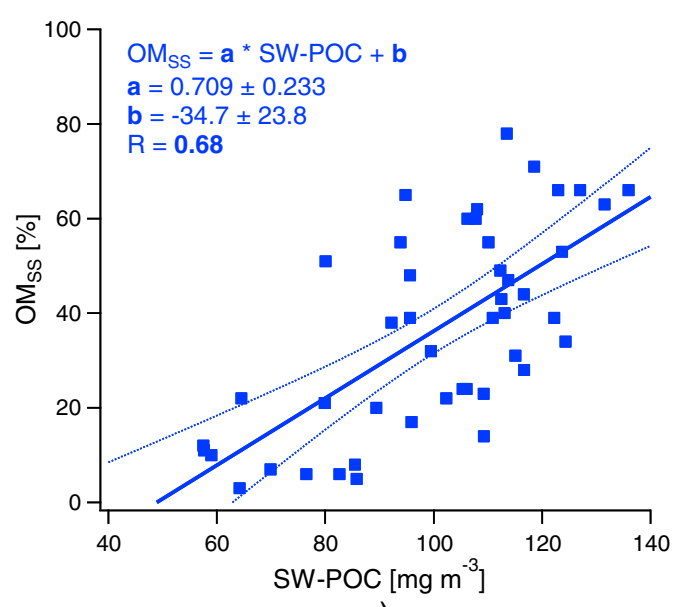

C)

Figure 5. Regression curves for (a) Chl-a, (b) CDM, and (c) SW-POC with $\mathrm{OM}_{\mathrm{SS}}$. Also reported are the correlation coefficients and the equation of the regression line. The dotted curves represent $95 \%$ confidence interval (CI). Error bars of the fit parameters refer to the $95 \%$ confidence interval. 


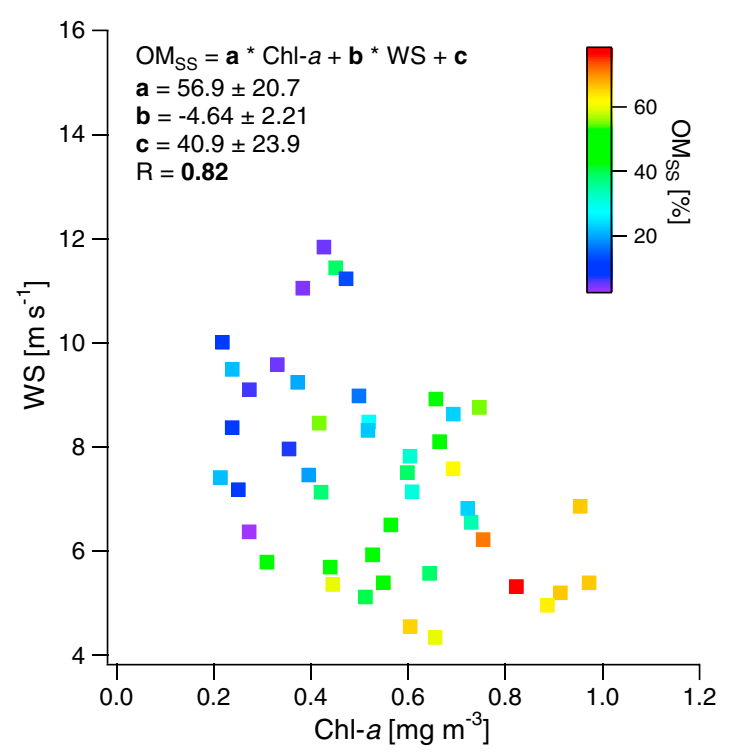

Figure 6. Scatterplot showing the relation between Chl- $a$, $\mathrm{WS}$, and $\mathrm{OM}_{\mathrm{SS}}$. The equation of the fitting curve resulting from the two-dimensional regression analysis is also reported. Uncertainties associated to the fit parameters refer to the $95 \%$ confidence interval.

parameterization, based on biological (Chl- $a$ ) and physical (WS) parameters, for implementation in large-scale models, to improve on the present capability of predicting the emission of submicron POA from oceans. The function was obtained using Chl- $a$ data with a time resolution of about 1 week and considering a time delay of 8 days between Chl- $a$ and the $\mathrm{OM}_{\mathrm{SS}}$ time series. Therefore, it is essential to consider such aspects when implementing the function in climate models. For example, if an atmospheric model is forced with monthly mean oceanic fields, the 8 day lag should be used when interpolating in time the fields needed for the function. Moreover, we recommend the use of the same Chl- $a$ input data as those used to derive the function (GlobColour data, derived from the merging of MERIS, MODIS, and SeaWiFS data), for better reliability of the predicted marine POA.

[36] The newly developed source function has several conditions. The maximum observed $\mathrm{OM}_{\mathrm{SS}}$ in the database was $78 \%$, which should be used as an upper limit for any combination of Chl- $a$ and WS values producing $\mathrm{OM}_{\mathrm{SS}}$ in excess of that value. At the lower end, certain combinations of Chl- $a$ and WS values will produce negative enrichment, e.g., for Chl- $a=0.1 \mathrm{mg} \mathrm{m}^{-3}$ and WS above $10 \mathrm{~m} \mathrm{~s}^{-1}$ or for any Chl- $a$ value $<0.9 \mathrm{mg} \mathrm{m}^{-3}$ if WS is above $20 \mathrm{~m} \mathrm{~s}^{-1}$. Therefore, the lower limit of $0 \%$ should be applied whenever $\mathrm{OM}_{\mathrm{SS}}$ becomes negative. It is also worth noting that the source function should not be used when WS is $<3-4 \mathrm{~m} \mathrm{~s}^{-1}$, which is the onset of whitecap and, therefore, of primary aerosol production. Finally, we would like to invite future users to be careful in extrapolating their modeling results at global level. The source function has been developed from measurements performed over the eastern North Atlantic Ocean, and at present, we are not able to predict if application at global level could result in significant biases of the modeled marine POA source or not.

[37] Although organic enrichment as a function of particle diameter was not considered in this study, we believe that the present function can be implemented also in size-resolved aerosol models, operating with due caution. For example, in Vignati et al. [2010], the previous source function was implemented in TM5-M7, where aerosol is treated by seven internally mixed modes, attributing the marine POA to the accumulation mode. This is reasonable, as PM1 measurements (on which the present and previous functions are based) are dominated by the accumulation mode in terms of mass. Finally, as for sea spray size distribution, we would recommend future users to follow the approach of O'Dowd et al. [2008] and Vignati et al. [2010], where a Chl-dependent modal diameter was adopted for marine POA, following the seasonal variation in the sea spray diameter observed by Yoon et al. [2007].

\section{Timescales of the Chl-a-OMSS Correlation}

[38] The correlation between Chl- $a$ and $\mathrm{OM}_{\mathrm{SS}}$, on which the sea spray source function parameterization is based, does not distinguish between the different timescales present in the signals. In practice, however, it is important to use the source function, to understand which temporal windows determine the observed correlation, and to ascertain whether timescales other than the mean seasonal variation are also correlated. In particular, the correlation between Chl- $a$ and $\mathrm{OM}_{\mathrm{SS}}$ can be generated by (1) the mean seasonal signal, (2) interannual variability (a slow modulation with a timescale longer than 1 year), and (3) "fast" fluctuations (timescale shorter than a year).

[39] To elucidate this point, the seasonal signal of both data sets was calculated by applying a moving average window filter ( 90 day width) to the data to eliminate short-term fluctuations and averaging the observations of the different years, to obtain a "climatological" seasonal signal. In this way, Chl- $a$ and $\mathrm{OM}_{\mathrm{SS}}$ mean seasonal variations were obtained, which were smooth over periods of less than 3 months. By removing the periodic signals from the measurements, Chl- $a$ and $\mathrm{OM}_{\mathrm{SS}}$ anomalies were obtained, which included both shortterm fluctuations and interannual variability. A lower, but still significant, correlation $(r=0.48)$ was observed between these anomalies, with the usual 8 day time lag, suggesting that the observed correlation was due not only to the seasonal signal but also to processes occurring on different timescales.

[40] To investigate the role of the mean seasonal signal in greater depth, surrogate time series were generated from the data set, by shuffling the sequence of the years. Thus, for both Chl- $a$ and $\mathrm{OM}_{\mathrm{SS}}$, the years in the 2002-2009 period were randomly reordered. For example, one surrogate signal was obtained from the measurements in 2006, followed by those of 2003, and so on. The operation cancels the correlations both in interannual variability and in the fluctuations at timescales shorter than 1 year, leaving only the mean seasonal signal. Considering 200 of the surrogate signals, we derived the confidence interval (CI; 95\%) for the null hypothesis that the correlation is solely 
due to the mean seasonal signal. For time lags from 2 to 13 days, the correlation in the data set exceeded this interval, confirming that interannual variability and/or faster fluctuations also play a role.

[41] The same approach was adopted to analyze the anomaly signals obtained by removing the true running mean from the Chl- $a$ data, obtained by continuously shifting a window of different widths along the time series. This removed from the Chl- $a$ data any variability at scales longer than the window length, retaining only the "faster" component. Unfortunately, the same could not be done for the $\mathrm{OM}_{\mathrm{SS}}$ data, due to the sparseness of the measurements. In this case, we removed the seasonal signal from $\mathrm{OM}_{\mathrm{SS}}$, as shown above. Following the previous approach, we tested against the null hypothesis of no correlation, by shuffling the measurement years. While, with a 60 and 90 day averaging window for Chl- $a$, the fast anomalies still presented significant correlations (with a peak at a lag of $8 / 9$ days), fluctuations faster than 30 days turned out to be undistinguishable from the surrogates falling within the $95 \%$ CI. In conclusion, no significant correlations were observed for fluctuations faster than 1 month, but at longer timescales (60 or 90 days), fluctuations faster than 1 year were recognized to be responsible for a significant correlation between $\mathrm{Chl}-a$ and $\mathrm{OM}_{\mathrm{SS}}$.

[42] The above findings support the idea that the organicinorganic source function parameterization obtained in this work is reliable for averaging timescales of 1 month and longer and that the seasonal signal plays a major role in determining the correlation between Chl- $a$ and $\mathrm{OM}_{\mathrm{SS}}$. It is therefore plausible that the reliability of the source function could be lower if applied in ocean areas characterized by a less pronounced seasonality of the Chl- $a$ concentration. To test this hypothesis quantitatively is very complex, however, given the lack of parallel submicron sea salt and WIOM measurements in unpolluted marine sites.

\section{Conclusion}

[43] The present study indicates that to date, chlorophyll- $a$ is the best biological activity surrogate available from satellite measurements for predicting the organic mass fraction of submicron sea spray, at least from measurements performed at Mace Head. In fact, considering the minimal difference between the correlation coefficient values between Chl- $a$, CDM, or SW-POC and $\mathrm{OM}_{\mathrm{SS}}$, there is no reason to substitute chlorophyll- $a$, which is the most accurate parameter obtained from ocean color data, with other biological surrogates which are generally affected by larger and less known errors.

[44] The results of this work show that the careful treatment of the satellite data is more important than the choice of the ocean color parameter in order to improve the correlation coefficient of the mixed organicinorganic sea spray source function. More specifically, the use of highly time-resolved satellite maps, with the appropriate treatment of the data voids, was able to reduce the dispersion of the data around the best fit line with respect to the previous approaches [O'Dowd et al., 2008; Vignati et al., 2010].

[45] The new approach experimented indicates that the oceanic region that exerts the maximum influence on the chemical composition of submicron sea spray aerosol measured at Mace Head is located between 47 and $57^{\circ} \mathrm{N}$ and between 14 and $24^{\circ} \mathrm{W}$. Moreover, it has evidenced a systematic delay of 8-10 days between the Chl- $a$, CDM, and SW-POC time series and $\mathrm{OM}_{\mathrm{SS}}$ that cannot be justified by the aerosol transport time. This delay could be related to the timescale of the biological processes responsible for the production of transferable organic materials during the bloom evolution. The time delay should be taken into account when modeling the production of primary organic aerosols from the oceans applying the present source function (equation (4)), as it was considered in developing the function itself. Nevertheless, given the limited resolution of the aerosol data, the relation between the observed time delay and the timescale of oceanic biological processes remains a hypothesis requiring further investigation in future studies. Additionally, even though demonstrated for the eastern North Atlantic Ocean, a certain caution should be entertained when dealing with other oceanic regions.

[46] A new relationship describing the organic enrichment of sea spray aerosol as a function of both wind speed and sea surface chlorophyll- $a$ concentration has been presented. The source function will contribute to improving the skill of present global models in predicting the production of submicron primary organic aerosols from the oceans. We believe that the proposed approach currently provides the most reliable tool for predicting the organic enrichment in sea spray aerosol and for estimating the magnitude of the primary organic aerosol source from the oceans.

\section{Appendix A}

[47] In the present work, multichannel singular spectrum analysis (M-SSA) was used to fill daily gaps in Chl- $a$, CDM, or SW-POC maps due to cloud cover or other environmental factors [Ghil et al., 2002; Kondrashov and Ghil, 2006]. This is a nonparametric method relying on data alone. It does not require the setting of any a priori parameter or model, which may introduce artificial oscillations that are not present in the "true" time series.

[48] The method uses both temporal and spatial correlations to fill in the missing points, and representing a generalization of the Beckers and Rixen [2003] spatial empirical orthogonal functions (EOFs) based reconstruction (RC), it is particularly useful for data sets that, as in our case, exhibit relatively long and continuous gaps [Kondrashov and Ghil, 2006].

[49] To illustrate the basic principles of the method, we briefly recall the basic equations for M-SSA. M-SSA is a generalization of its univariate version (SSA) to a multivariate $L$-channels time series:

$$
\left\{X_{l}(t): l=1, \ldots, L ; t=1, \ldots, N\right\}
$$

[50] In our case, $L$ is the number of sea grid points and $N$ is the length of the time series, i.e., the number of ocean color maps.

[51] The approach used to compute the lagged cross covariance [Broomhead and King, 1986a, 1986b] is to form a matrix 
$\widetilde{X}$ by first augmenting each channel $\left\{\boldsymbol{X}_{l}(t): t=1, \ldots, N\right\}$ of $\mathbf{X}$ with $M$ lagged copies of itself:

$$
\widetilde{X}_{l}=\left(\begin{array}{ccccc}
X_{l}(1) & X_{l}(2) & \cdot & \cdot & X_{l}(M) \\
X_{l}(2) & X_{l}(3) & \cdot & \cdot & X_{l}(M+1) \\
\cdot & \cdot & \cdot & \cdot & \cdot \\
X_{l}\left(N^{\prime}-1\right) & \cdot & \cdot & \cdot & X_{l}(N-1) \\
X_{l}\left(N^{\prime}\right) & X_{l}\left(N^{\prime}+1\right) & \cdot & \cdot & X_{l}(N)
\end{array}\right)
$$

where $1 \leq l \leq L$ and $N^{\prime}=N-M$. The lag covariance matrix is then given by

$$
\widetilde{C}_{X}=\frac{1}{N}, \widetilde{X}^{T} \widetilde{X}=\left(\begin{array}{cccccc}
C_{1,1} & C_{1,2} & \cdot & \cdot & \cdot & C_{1, L} \\
\cdot & C_{2,2} & \cdot & \cdot & \cdot & \cdot \\
\cdot & \cdot & \cdot & \cdot & C_{l, l} & \cdot \\
\cdot & \cdot & \cdot & \cdot & \cdot & \cdot \\
\cdot & \cdot & \cdot & \cdot & \cdot & \cdot \\
C_{L, 1} & C_{L, 2} & \cdot & \cdot & \cdot & C_{L, L}
\end{array}\right)
$$

an $L M \times L M$ matrix with blocks

$$
C_{l, l^{\prime}}=\frac{1}{N} \widetilde{X}_{l}^{T} \widetilde{X}_{l}
$$

[52] The diagonalization of the covariance matrix gives the eigenvectors $\left\{\boldsymbol{E}^{k}: 1<k \leq L M\right\}$ and the eigenvalues $\lambda_{k}$. The space-time principal components, i.e., the projection of the data onto the EOFs, are

$$
A^{k}(t)=\sum_{j=1}^{M} \sum_{l=1}^{L} X_{l}(t+j-1) E_{l}^{k}(j)
$$

where $t$ varies from 1 to $N^{\prime}$.

[53] Finally, the time series can be reconstructed using a linear combination of the principal components:

$$
R_{l}^{K}(t)=\frac{1}{M_{t}} \sum_{j=L_{t}}^{U_{t}} A^{k}(t-j+1) E_{l}^{k}(j)
$$

where $K$ is the set of EOFs on which the reconstruction is based. $M_{t}$ and the interval $L_{t}$ to $U_{t}$ are as long as $M$ in the central part of the time series while smaller near the endpoints [see Ghil et al., 2002, equation 12].

[54] Based on this reconstruction (RC) formula, the sequence of steps for the gap filling is as follows.1.

The original time series is centered by computing the unbiased value of the mean and setting the missing data to zero.1.

The first EOF $\mathbf{E}_{1}$ of this time series is computed, and a new time series is reconstructed with this EOF-alone RC $\mathbf{R}_{1} .1$. SSA is performed again on RC $\mathbf{R}_{1} .1$.

The reconstruction is repeated using the new $\mathbf{R}_{1}$ and tested against the previous one, until a convergence test has been satisfied.

[55] The process is repeated for each chosen EOF, starting from the solution with data filled in by $\mathbf{R}_{1}$ and repeating the inner iteration.

[56] It is important to underline that the above method can neither create phytoplankton signals that are not already present in the input data nor produce new oscillatory modes. Nevertheless, the interpolation error still depends on the amount and distribution of the available input data.
[57] Kondrashov and Ghil [2006] demonstrated that an increased number of gaps yield the same effect of increasing the noise in the measurements. The most uncertain situation occurs in the presence of a long, continuous gap of data corresponding to a very persistent overcast period. Even in this case, Kondrashov and Ghil [2006] showed that the period of the oscillation can be determined correctly, provided the gap is not larger than any significant spatial-temporal correlations present in the data, i.e., the time period of the slowest oscillatory mode. This means that a gap of a few weeks does not preclude the determination of the oscillatory modes that describe the seasonal variability present in our time series.

[58] Previous works based on the Beckers and Rixen [2003] method, which is a particular case of M-SSA, have demonstrated that the bias and root-mean-square (RMS) errors between interpolated ocean color and in situ data do not differ from the corresponding one when only real measured satellite data are used [Volpe et al., 2012]. Finally, Kondrashov and Ghil [2006] showed that the interpolation RMS error depends on the choice of the window length and is always lower than the corresponding RMS error obtained using the Beckers and Rixen [2003] method, by approximately $40 \%$ for $M$ greater than about 40 . Even if we do not have available in situ measurements to repeat the Volpe et al. [2012] estimation for our area of investigation, the above consideration suggests that also in our case, the interpolation did not introduce undesirable biases in the analyzed field.

[59] Acknowledgments. This work was supported by the EU projects MAP (Marine Aerosol Production), MyOcean, and PEGASOS (Pan-European Gas-Aerosols-climate interaction Study) and by the Irish EPA projects EASIAQCIS (Exchange at the Air-Sea Interface: Air Quality and Climate Impacts) and Research Support for Mace Head. ACCENT (Atmospheric Composition Change the European Network of Excellence) is also gratefully acknowledged. The satellite products used in this paper were processed and distributed by ACRI-ST GlobColour service, supported by the EU FP7 MyOcean and ESA GlobColour projects, using ESA Envisat MERIS and NASA MODIS and SeaWiFS data.

\section{References}

Beckers, J., and M. Rixen (2003), EOF calculations and data filling from incomplete oceanographic data sets, J. Atmos. Ocean. Technol., 20, 1839-1856.

Broomhead, D. S., and G. P. King (1986a), Extracting qualitative dynamics from experimental data, Phys. D, 20, 217-236.

Broomhead, D. S., and G. P. King (1986b), On the qualitative analysis of experimental dynamical systems, in Nonlinear Phenomena and Chaos, edited by S. Sarkar, pp. 113-144, Adam Hilger, Bristol, England.

Cavalli, F., et al. (2004), Advances in characterization of size-resolved organic matter in marine aerosol over the North Atlantic, J. Geophys. Res., 109, D24215, doi:10.1029/2004JD005137.

Ceburnis, D., C. D. O’Dowd, G. S. Jennings, M. C. Facchini, L. Emblico, S. Decesari, S. Fuzzi, and J. Sakalys (2008), Marine aerosol chemistry gradients: Elucidating primary and secondary processes and fluxes, Geophys. Res. Lett., 35, L07804, doi:10.1029/2008GL033462.

Ceburnis, D., et al. (2011), Quantification of the carbonaceous matter origin in submicron marine aerosol by $13 \mathrm{C}$ and $14 \mathrm{C}$ isotope analysis, Atmos. Chem. Phys., 11, 8593-8606, doi:10.5194/acp-11-8593-2011.

Decesari, S., et al. (2011), Primary and secondary marine organic aerosols over the North Atlantic Ocean during the MAP experiment, J. Geophys. Res., 116, D22210, doi:10.1029/2011JD016204.

Facchini, M. C., et al. (2008), Primary submicron marine aerosol dominated by insoluble organic colloids and aggregates, Geophys. Res. Lett., 35, L17814, doi:10.1029/2008GL034210.

Gantt, B., N. Meskhidze, and D. Kamykowski (2009), A new physically-based quantification of marine isoprene and primary organic aerosol emissions, Atmos. Chem. Phys., 9, 4915-4927, doi:10.5194/acp-9-4915-2009.

Gantt, B., N. Meskhidze, M. C. Facchini, M. Rinaldi, D. Ceburnis, and C. D. O'Dowd (2011), Wind speed dependent size-resolved parameterization for 


\section{RINALDI ET AL.: CHLOROPHYLL AND OM IN FINE SEA SPRAY}

the organic mass fraction of sea spray aerosol, Atmos. Chem. Phys., 11, 8777-8790, doi:10.5194/acp-11-8777-2011.

Gregg W. W., and N. W. Casey (2007), Sampling biases in MODIS and SeaWiFS ocean chlorophyll data, Remote Sens. Environ., 111, 25-35.

Ghil, M., et al. (2002), Advanced spectral methods for climatic time series, Rev. Geophys., 40, (1), 1003, doi:10.1029/2000RG000092.

Kondrashov, D., and M. Ghil (2006), Spatio-temporal filling of missing points in geophysical data sets, Nonlin. Processes Geophys., 13, 151-159.

Ito, A., and M. Kawamiya (2010), Potential impact of ocean ecosystem changes due to global warming on marine organic carbon aerosols, Global Biogeochem. Cycles, 24, GB1012, doi:10.1029/2009GB003559.

Keene, W. C., et al. (2007), Chemical and physical characteristics of nascent aerosols produced by bursting bubbles at a model air-sea interface, J. Geophys. Res., 112, D21202, doi:10.1029/2007JD008464.

Langmann, B., C. Scannell, and C. D. O'Dowd (2008), New Directions Organic matter contribution to marine aerosols and cloud condensation nuclei, Atmos. Environ., 42, 7821-7822.

Long, M. S., W. C. Keene, D. J. Kieber, D. J. Erickson, and H. Maring (2011), A sea-state based source function for size- and compositionresolved marine aerosol production, Atmos. Chem. Phys., 11, 1203-1216, doi:10.5194/acp-11-1203-2011.

Maritorena, S., and D. A. Siegel (2005), Consistent merging of satellite ocean color data sets using a bio-optical model, Remote Sens. Environ., 94(4), 429-440.

Maritorena S., O. H. Fanton d'Andon, A. Mangin, and D. A. Siegel (2010), Merged satellite ocean color data products using a bio-optica model: Characteristics, benefits and issues, Remote Sens. Environ. 114 1791-1804.

Myriokefalitakis, S., et al. (2010), Global modeling of the oceanic source of organic aerosols, Adv. Meteorol., 939171, doi:10.1155/ 2010/939171.

O'Dowd, C. D., M. C. Facchini, F. Cavalli, D. Ceburnis, M. Mircea, S. Decesari, S. Fuzzi, Y. J. Yoon, and J.-P. Putaud (2004), Biogenically driven organic contribution to marine aerosol, Nature, 431, 676-680, doi: 10.1038 /nature 02959 .

O'Dowd, C. D., B. Langmann, S. Varghese, C. Scannell, D. Ceburnis, and M. C. Facchini (2008), A combined organic-inorganic sea-spray source function, Geophys. Res. Lett., 35, L01801, doi:10.1029/ 2007GL030331.
O'Dowd, C., C. Monahan, and M. Dall'Osto (2010), On the occurrence of open ocean particle production and growth events, Geophys. Res. Lett., 37, L19805, doi:10.1029/2010GL044679.

Ovadnevaite, J.,C. D. O’Dowd, M. Dall'Osto, D. Ceburnis, D. R. Worsnop, and H. Berresheim (2011), Detecting high contributions of primary organic matter to marine aerosol: A case study, Geophys. Res. Lett., 38, L02807, doi:10.1029/2010GL046083.

Rinaldi, M., et al. (2009), On the representativeness of coastal aerosol studies to open ocean studies: Mace Head-A case study, Atmos. Chem. Phys., 9(24), 9635-9646.

Roelofs, G. J. (2008), A GCM study of organic matter in marine aerosol and its potential contribution to cloud drop activation, Atmos. Chem. Phys. 8, 709-719.

Shank, L. M., S. Howell, A. D. Clarke, S. Freitag, V. Brekhovskikh, V. Kapustin, C. McNaughton, T. Campos, and R. Wood (2012), Organic matter and non-refractory aerosol over the remote southeast Pacific: Oceanic and combustion sources, Atmos. Chem. Phys., 12, 557-576, doi: $10.5194 / \mathrm{acp}-12-557-2012$.

Spracklen, D., et al. (2008), Globally significant oceanic source of organic carbon aerosol, Geophys. Res. Lett., 35, L12811, doi:10.1029/ 2008GL033359.

Stramska, M. (2009), Particulate organic carbon in the global ocean derived from SeaWiFS ocean color, Deep-Sea Res. I, 56, 1459-1470, doi:10.1016/j.dsr.2009.04.009.

Vignati, E., et al. (2010), Global scale emission and distribution of seaspray aerosol: Sea-salt and organic enrichment, Atmos. Environ., 44 670-677, doi:10.1016/j.atmosenv.2009.11.013.

Volpe, G., B. Buongiorno Nardelli, P. Cipollini, R. Santoleri, and I. S. Robinson (2012), Phytoplankton response to physical processes: EOF analysis of satellite observations, Remote Sens. Environ., 117, 223-235.

Wang, M. (2002), The Rayleigh lookup tables for the SeaWiFS data processing: Accounting for the effects of ocean surface roughness, Int J. Remote Sens., 23, 2693-2702.

Westervelt, D. M., R. H. Moore, A. Nenes, and P. J. Adams (2012), Effect of primary organic sea spray emissions on cloud condensation nuclei concentrations, Atmos. Chem. Phys., 12, 89-101, doi:10.5194/ acp-12-89-2012.

Yoon, Y. J., et al. (2007), Seasonal characteristics of the physicochemical properties of North Atlantic marine atmospheric aerosols, J. Geophys. Res., 112, D04206, doi:10.1029/2005JD007044 